\title{
Creating Strong Listening Environments: A Key Hospitality Management Task
}

Judi Brownell

Cornell University

Forthcoming in International Journal of Contemporary Hospital Management

\begin{abstract}
The listening environment is viewed as an aspect of organizational culture that both influences and is influenced by individual behaviour. Discusses the concept of the listening environment within hospitality organizations from a symbolic/culture perspective. Examines the ways in which this environment influences both the accomplishment of organizational tasks and the development of interpersonal relationships on the job. Suggests that managers can deliberately control many aspects of the listening environment, and that effective hospitality leaders foster strong listening environments as one approach to increasing employee participation, excellent guest service and organizational commitment.
\end{abstract}

Keywords: corporate culture, employee attitudes, hospitality industry, listening, management techniques, organizational behavior, organizational change, quality 


\section{Creating Strong Listening Environments: A Key Hospitality Management Task}

Hospitality managers function in an environment characterized by rapid change, in an age where technology has increased demands on service workers and where the lens of internationalism frames their vision of the years ahead. The hospitality workforce and the guests they serve are becoming increasingly diverse. The ageing of the population, too, now requires a heightened understanding of how individuals adapt to new relationships, new behaviors, and new services [1,2]. There is no question that the need for effective communication in today's hospitality settings is critical [3-6].

Many researchers persuasively argue that managers of the future can succeed only if they are willing to consider the unpredictable dimensions of organizational life dimensions that characterize the fast-paced hospitality environment. Most of today's theorists have moved from highly rational models to perspectives that take into account the individualistic, dynamic characteristics of service organizations [7-10]. Hospitality managers moving into the twenty-first century, charged with the tasks of motivating, coaching, and mentoring service employees, must now focus on one of the most central yet neglected aspects of communication - effective listening [11-13].

This article focuses on the impact hospitality managers' listening behavior has on key organizational dimensions. The concept of the listening environment is presented, and its importance as an organizational variable is examined. The subjective nature of listening environments is discussed from a symbolic/culture perspective. The effect of strong listening environments on both the task and relationship dimensions of hospitality management is then explored. Finally, the usefulness of this concept is suggested as hospitality managers seek to improve both individual and organizational effectiveness. 
We begin with a definition of the listening environment.

\section{Perceptions of Listening and the Listening Environment}

It is likely that hospitality organizations in the years ahead will be characterized by a growing emphasis on transformational leaders, individuals who are convinced that their role "is not to control people and stay 'on top' of things, but rather to guide, energize, and excite" [14, p. 30]. As effective organizational leaders begin to flatten the traditionally steep administrative pyramid, each hospitality manager has increased opportunities to influence employees' performance, not only by setting policies and distributing rewards, but also through his or her specific communication practices. Key among these is a manager's listening behavior.

It seems appropriate to refer to the aspect of corporate culture that influences and defines listening behavior as a listening environment. Strong listening environments are characterized by a concern for the individual employee and his or her values, needs, and goals. Peters was among the first to use the term, describing a listening environment as one in which managers "listen to their people" and teammates listen to one another [15, p. 367]. In recent literature, the concept of employee empowerment captures the attitude fostered by effective listening.

Strong listening environments have been assumed to promote a free and open exchange of ideas and information among all organizational members [16]. As with similar concepts such as communication climate [17-19], a listening environment is defined by a set of characteristics that are relatively enduring over a period of time. These characteristics contribute to the development of common perceptions among 
organizational members. Signs of a strong listening environment range from managers' non-verbal cues to open office doors and listening slogans tacked on bulletin boards. While specific behaviors and non-verbal elements contribute to the perception of the listening environment, these perceptions, once established, influence employees' attitudes and subsequent behavior [1,20]. Since employees' guest contact behavior is often a critical part of a guest's service experience, any systems which facilitate positive employee practices are particularly relevant to the hospitality industry.

Perceptions of listening in hospitality environments are affected by a number of variables [21]. Employees' specific background, culture, and role relationships - as well as their attitudes, personal agendas, and values - influence how a particular set of behaviors will be experienced. The diversity of the hospitality workforce, as one might imagine, complicates this process still further. There is little question, for instance, that, while in one organization frequent meetings and memoranda may be perceived as timeconsuming and tedious, in another case organizational members may interpret these activities as a means of facilitating employee involvement and information sharing. While a manager who walks around is viewed as interested and accessible in organization A, she may well be perceived as unproductive in organization $\mathrm{B}$.

The listening environment, then, emerges out of the interactions that members of a work group have with one another [22] and employees' subsequent interpretations of their meaning. As service managers know well, "objective performance is for the most part an illusion ... the critical dimension is how that performance is perceived" [23, $p$. 55]. An understanding of this symbolic process is helpful in managers' efforts to understand, and to create, strong listening environments. 
When we discuss listening in hospitality contexts, therefore, we are referring to listening effectiveness as it is perceived by members of that organization. It is employees' perceptions of the listener - with all of the accompanying assumptions regarding such factors as attitude, motive, and purpose - that influence his or her interpretations and subsequent response (Figure 1). As Lewis and Reinsch note, speakers use "observable behaviors to form impressions of unobservable internal, mental processes" [21, p. 64].

Recent studies [21, 24, 25] suggest that the meanings assigned to the word listening vary from one property to the next, and from the academic to the organizational environment. When employees complain that their manager "doesn't listen," they may mean that he or she doesn't look at them, interrupts them when they speak, or that the manager demonstrates any number of other behaviors perceived by the employee as "not listening". Neither researchers nor practitioners have agreed on one definition of the listening process $[25,26]$, and researchers have begun to realize that perceptions of an individual's listening ability may not correspond so closely as we would expect to the scores he or she receives on standardized listening tests [27-29].

Few doubt that listening in work environments is a complex activity [5,30-32]. When studying listening environments, a non-unitary, behavioral approach has several advantages over definitions that emphasize the more covert, cognitive aspects of listening $[5,21,25]$. First, specified behaviors can be readily identified and used by observers in determining listening effectiveness. 
Behavioral approaches also assume that individuals can become more effective through deliberate modifications or changes in existing behavioral patterns. There is no question that learning to "do the right things" can influence observers' impressions and enhance the listening environment.

The HURIER model of listening [33] is one example of a behavioral approach to understanding and practicing effective listening in hospitality organizations. The listening process is viewed as six interrelated skill areas: hearing, understanding, interpreting, remembering, evaluating, and responding (Figure 2). Studies using this model have concluded that employees do perceive managers' listening in terms of separate but interrelated components.

It is not surprising that one individual also listens more or less well according to his or her level of motivation - the value that he or she places on listening in a particular context. For instance, while middle hospitality managers were perceived as very good listeners by their supervisors, secretaries generally gave these managers much lower ratings [24]. The fact that motivation plays a significant role in determining listening behavior may explain discrepancies between standardized test scores and perceptions of performance on the job. Owing to the complexities of the process, it is not surprising that substantial problems in assessing listening competence have plagued educators and researchers alike $[34,35]$.

Since we know that individuals interpret their experiences and assign meanings according to their personal backgrounds, those managers who strive to create strong listening environments must consider a number of complex variables in planning a course of action. People are often non-rational; employees may interpret management's 
actions in unanticipated ways [36]. They may also react to present behaviors in terms of previous encounters and the motives they assign to the behavior they witness [21].

Although researchers and practitioners alike have emphasized the importance of effective listening [11, 37], surprisingly little is known about the precise ways in which listening influences individuals and organizations. The next sections examine some critical questions regarding the significance of listening environments to the hospitality industry.

\section{Listening Environments: A Look at What We Know}

There is no question that the decades ahead will be characterized by an increasing emphasis on human resources practices. This movement reinforces the importance of effective managerial communication in satisfying employees' needs, in improving individual performance and, hence, in increasing guest satisfaction [38]. Specialists have come to look at the quality of work life, the "service within," largely in terms of employee attitudes and the nature of the relationships that develop on the job. These relationships, in turn, affect individuals' perceptions of the work environment and determine how members will experience organizational life. If McGregor's [39] hypothesis is sound, people will work harder if they are given opportunities to affiliate with their peers, express their creativity, and participate in decision-making processes.

Employees' perceptions of certain internal organizational conditions facilitate their involvement and performance; yet, the exact nature of such environments is difficult to specify [40]. Whatever the frustrations, the growing emphasis on the effect of organizational environments on employee growth and development is a step towards 
the recognition of the importance of listening in hospitality settings. Our emphasis is on how an individual's actions influence the quality and nature of listening in organizational settings. Having discussed the nature of listening and listening environments, we are now interested in its effect on organizational members.

\section{The Influence of the Listening Environment on Task and Relationship Dimensions}

The concept of the listening environment is a complex, somewhat ambiguous construct. Although researchers, educators, and practitioners alike have placed increasing emphasis on listening in organizations [2, 21, 31], far too little evidence exists to support our notions regarding the value of this activity. Our assumptions that a strong listening environment leads to increased productivity, greater job satisfaction, reduced absenteeism, grievances, and turnover, and generally increased organizational commitment, have not been fully substantiated. The concern for effective listening clearly has not been paralleled by research in the field.

Just how much do we really know about the impact of listening environments on a hospitality organization's employees and their performance? The literature to date suggests that there are two "higher order factors" undergirding listening behavior in organizations. These appear to be: the exchange of accurate information to accomplish organizational tasks, and the facilitation of a supportive interpersonal communication environment [12, 31]. A strong listening environment, then, may well influence both productivity and work satisfaction (Table 1). The next section examines organizational listening as it relates to these two purposes. 


\section{Task-related Findings}

A fundamental premise of the early human relations movement was that happy workers are more productive workers [38]. If this is the case, the existence of a strong listening environment and the subsequent "good feelings" would have a direct impact on performance. Research, however, has not substantiated this claim. No purely causal relationship between satisfaction and performance has yet to be conclusively drawn [41]. What does seem to hold true is that appropriate rewards and recognition, based on high job performance, lead to satisfaction and subsequently to continuing high performance. Listening becomes relevant as managers select appropriate rewards and reinforce desirable behaviors. It appears that excellence is achieved only by an employee who is heard - quite literally - and who is given the opportunity to participate and to contribute. In this case, it is the manager's appropriate "listening response" to what he or she hears that improves subordinates' motivation.

Further research has determined that workers who have direct and frequent communication with their managers are less likely to file grievances. They learn new tasks more readily and have fewer accidents. Absenteeism and turnover are also decreased [42]. It also seems safe to conclude that a strong listening environment encourages accurate information sharing. Managers who understand employee needs and concerns can help them to perform more effectively by examining elements of job design, selecting appropriate rewards, and providing timely recognition for employees' accomplishments. Successful job performance and the subsequent rewards increase employee satisfaction, which in turn leads to increased motivation and higher quality guest service. 
Effective listening also reduces costly misunderstandings. Time is wasted, costs increased, guests dissatisfied, morale deflated, and job anxiety heightened as a result of poor listening $[11,43]$. Accurate and continuous information sharing is an essential element of high-performing hospitality organizations [44, 45], especially in coordinating activities and services across departmental boundaries.

In one case study [2] researchers discovered that when tasks are routine, listening behavior has little influence on productivity. When tasks were novel and changing, as they are in hospitality organizations, listening ability had a significant impact on performance. Similarly, effective listening contributes to employees' ability accurately to process information required for problem solving [46]. As individuals confront a wide range of guest demands and a constantly changing work environment, listening will become an increasingly important survival skill.

Strong listening environments increase productivity, but what about the environment's influence on the individual employee and his or her relationships on the job? The next section reviews the impact of the listening environment on the interpersonal dimensions of the workplace.

\section{Relationship Concerns}

When the most desirable organizational values are identified, interpersonal trust emerges as a recurring theme [47]. Trust is at the core of all relationships, influencing the nature and quality of communication on the job. Several researchers [48-50] have suggested that trust develops through effective listening, and that the process is reciprocal. If supervisors listen carefully to employees' problems, subordinates are likely 
to respond by listening both to their fellow employees and to their guests. In this regard, listening is also a tool for empowerment, encouraging the disclosure and sharing of information at all levels of the organization.

Employees' psychological health and sense of wellbeing are also related to their perceptions of whether or not anyone listens to them; these perceptions, in turn, have a direct influence on workers' productivity [1,51]. Campbell's [52] study of women supports this hypothesis. Following her interviews, her subjects reported feeling not only understood but also empowered by the process. Her only technique was active listening. Clearly, a greater concern for the total individual appears to encourage healthier communication encounters on the job and directly impacts on service quality. In traditional environments, employees often have been conditioned to suppress their personal feelings and intuition, perhaps as a means of self-protection. If managers are able to provide their employees with a more positive, open communication climate on the job, employees are likely to respond by sharing their excitement with colleagues and guests. The new "commitment-based approach" [53,54] calls not only for high performance expectations but also for authentic and empathic communication as well. In such cases, guests cannot help but benefit from service employees' positive attitudes.

Unfortunately, at least one study [24] suggests that managers are most lacking in skills related to empathic listening. Not only are employees' perceptions of their manager's ability lowest on this dimension (interpreting messages), but also discrepancies between managers' self-perceptions and employees' perceptions of their manager's behavior are significant. The good news is that empathic listening can be 
taught [55]. The message has become clear: managers must listen to their employees, and they must indicate that they hear both the substance and the emotional aspects of the messages conveyed.

\section{Managers' Influence on the Listening Environment}

As we have seen, the listening environment is an organizational dimension that influences employees' behavior as it is created by the specific communication practices of the organizational members themselves [56]. Strong listening environments facilitate information exchange and enable managers to respond more appropriately to individual employee concerns.

As specific organizational variables change, however, managers must be quick to respond by re-examining their listening environments and making appropriate adjustments. One of the basic assumptions of our behavioral perspective is that managers can deliberately intervene to establish strong listening environments [57]. As culture leaders [58-60], either within organizations or work groups, hospitality managers must take responsibility for ensuring that employees feel free to exchange information in a timely and accurate manner. They must foster and reward employee behaviors that promote healthy relationships both within and outside of the organization.

Although each employee's perceptions of their organization's listening environment are unique and subjective, managers influence these perceptions through their own actions and communication behaviors (Figure 3). If all business is truly show business [61, p. 311], then managements' show portrays the organization's most fundamental values and assumptions. As role models, effective managers practice the 
skills of effective listening in their daily activities; as coaches and facilitators, effective managers support listening training for employees organization-wide [2, 62].

Managers create strong listening environments, then, by demonstrating behaviors that are perceived and interpreted by employees as indicators of effective listening. The HURIER model suggests that effective listeners concentrate on the speaker, hear messages accurately, consider the emotional as well as the content aspects of a message, remember what was said to them, and remain non-judgemental, while listening to the speaker's ideas (see Appendix). Managers' appropriate response to organizational events also influences employees' perceptions of their listening ability [24]. When managers value listening, they spend time engaging in listening-related behaviors. They walk around, they ask questions, they follow through on their promises. These supportive behaviors, in turn, promote a service atmosphere.

Leaders also demonstrate that listening is valued by creating physical environments that encourage effective listening behavior [2,63]. Open doors and informal meeting areas encourage communication, as do well lit, ventilated, comfortable spaces [64]. Listening environments are also symbolized through cultural artifacts. The prominent display of the property's newsletter or the availability of flip charts and bulletin boards send messages to employees regarding the value placed on listening. From personalized coffee cups (we're always ready to sit down and talk) to suggestion boxes, managers as culture leaders symbolize their values in tangible forms as they work to create shared meanings among employees.

When listening environments are strong, employees have a shared vision of the organization's mission and of what quality service means. They understand their job 
and how it contributes to accomplishing larger organizational goals. Fewer mistakes are made, and information is received in a more timely and accurate fashion. Effective listening reduces the anxiety that accompanies rapid and constant change. Employees feel free to seek as well as to share information that helps them adjust to new work environments and new job responsibilities. Mutual respect and understanding are increased among members of multicultural workforces. A sense of trust, team spirit and job commitment characterizes hospitality organizations that have developed strong listening environments.

\section{Conclusion}

Managers who look ahead to the twenty-first century may well discover that their primary objective is to listen well and to behave in ways that reinforce employees' perceptions of being heard. Those managers who view their role as coach and facilitator work to increase employees' involvement and commitment. Much of this is accomplished through effective listening.

The twenty-first century will see many important changes in both hospitality organizations and their workforces. Educators and practitioners must begin to ask questions - questions that recognize this changing world view, questions such as: What does the concept of the listening environment mean to establishing and maintaining quality service? How does it relate to our concerns with valuing diversity, exploding information technologies, or organizational change itself?

The emphasis on effective listening speaks to values that define our developing sense of what all service organizations in the decades ahead should be like. Values like 
integrity, co-operation, trustworthiness, and caring may be realized most fully within the context of listening environments. It may be frightening to put these principles to the test in an effort to determine whether, in fact, they do make a difference; it may be even more frightening to lose sight of these goals as rapid and unpredictable changes sweep us into an uncertain future. The vision of strong listening environments may foster practices and attitudes that become the most important tools hospitality managers bring with them into the twenty-first century. 


\section{References}

1. Lindley, C.J., "Putting 'Human' into Human Resource Management”, Public Personnel Management, Vol. 13 No. 4, Winter 1984, pp. 501-10.

2. Papa, M.G. and Glenn, E.C., "Listening and Performance with New Technology", The Journal of Business Communication, Vol. 25 No. 4, 1988, pp. 5-15.

3. DiSalvo, V.S., "A Summary of Current Research Identifying Communication Skills in Various Organizational Contexts", Communication Education, Vol. 29, 1980, pp. 283-90.

4. Rhodes, S.C., "Specific Listening Skills Important in Organizations", Communication Research Bulletin, Vol. 7 No. 4, 1985, pp. 1-2.

5. Sypher, B.D., Bostrom, R.N. and Seibert, J.H., "Listening Communications Abilities, and Success at Work", Journal of Business Communication, Vol. 26 No. 4, 1989, pp. 293-303.

6. Stegman, J.D., "The Importance of Managerial Communication: An Annotated Bibliography", The ABC Bulletin, Vol. 51 No. 3, 1988, pp. 25-6.

7. Weick, K.E., The Social Psychology of Organizations, Random House, New York, NY, 1979.

8. Bolman, L.G. and Deal, T.E., Modern Approaches to Understanding and Managing Organizations, Jossey- Bass, San Francisco, CA, 1983.

9. Lundberg, C.C., "Surfacing Organizational Culture", Journal of Managerial Psychology, Vol. 5 No. 4, 1990.

10. Moss-Kanter, R., The Change Masters: Innovation for Productivity in the American Corporation, Simon \& Schuster, New York, NY, 1983. 
11. Steil, L.K., Barker, L.L. and Watson, K.W., Effective Listening: Key to Your Success, Random House, Reading, MA, 1983.

12. Hunt, G.T. and Cusella, L.P., "A Field Study of Listening Needs in Organizations", Communication Education, Vol. 32, 1983, pp. 398-407.

13. Brownell, J., "Listening Environments", in Wolvin, A. and Coakley, C.G. (Eds), Perspectives on Listening, University Press, New York, NY, 1992.

14. Yammarlo, F.J., Spangler, W.D. and Bass, B.M., "Transformational Leadership and Performance: A Longitudinal Investigation", Leadership Quarterly, Vol. 4 No. 1, 1993, pp. 81-102.

15. Peters, T., Thriving on Chaos, Alfred A. Knopf, New York, NY, 1988.

16. King, C.P., "Keep your Communication Climate Healthy", Personnel Journal, Vol. 57 No. 4 April 1978, pp. 204-06.

17. Ireland, R.D., Van Auken, P.M. and Lewis, P.V., "An Investigation of the Relationship between Organization Climate and Communication Climate", Journal of Business Communication, Vol. 16 No. 1, Fall 1978, pp. 3-10.

18. Joyce, W.F. and Slocum, J., "Climate Discrepancy: Refining the Concepts of Psychological and Organizational Climate", Human Relations, Vol. 35 No. 11, November 1982, pp. 951-71.

19. Muchinsky, P.M., "Organizational Communication: Relationships to Organizational Climate and Job Satisfaction", Academy of Management Journal, Vol. 20 No. 4, December 1977, pp. 592-607.

20. Ashworth, D.M. and Meglino, B.M., "Organizational Climate and Employee Performance", Mid-Atlantic Journal of Business, Vol. 21 No. 1, Winter 1983, pp. 1-8. 
21.Lewis, M.H. and Reinsch, N.L. Jr, "Listening in Organizational Environments", The Journal of Business Communication, Vol. 25 No. 3, 1988, pp. 49-67.

22. Schneider, B. and Reichers, A.E., "On the Aetiology of Climate", Personnel

Psychology, Vol. 36 No. 1, 1983, pp. 19-39.

23. Caballero, M. and Dickinson, R., "Beyond Rationality", Business Horizons, Vol. 27 No. 4, July-August 1984, pp. 55-68.

24. Brownell, J., "Perceptions of Effective Listeners: A Management Study", The Journal of Business Communication, Vol. 27 No. 4, 1990, pp. 401-16.

25. Glenn, E.C., "A Content Analysis of 50 Definitions of Listening", Journal of the International Listening Association, Vol. 3, 1989, pp. 21-31.

26. Witkin, B.R., "Listening Theory and Research: The State of the Art", Journal of the International Listening Association, Vol. 4, 1990, pp. 7-32.

27. Brown, J.I. and Carlson, G.R., Brown-Carlson Listening Comprehension Test, Harcourt, Brace and World, New York, NY, 1955.

28. Watson, K. and Barker, L., Watson-Barker Listening Test, Spectra, New Orleans, LA, 1984.

29. Bostrom, R., The Kentucky Comprehensive Listening Test, Listening Research Center, Lexington, MA, 1983.

30. Gilbert, M., Perceptions of Listening Behaviours of School Principals, paper presented at the ILA Convention, Atlanta, GA, March 1989.

31. Husband, R.L., Cooper, L.O. and Monsour, W.M., "Factors Underlying Supervisors' Perceptions of Their Own Listening Behavior", Journal of the International Listening Association, Vol. 2, 1988, pp. 97-112. 
32. Bostrom, R.N. and Waldhart, E.S., "Memory Models and the Measurement of Listening", Communication Education, Vol. 37, 1988, pp. 1-13.

33. Brownell, J., Building Active Listening Skills, Prentice- Hall, Englewood Cliffs, NJ, 1986.

34. Rhodes, S.C., Watson, K.W. and Barker, L.L., "Listening Assessment: Trends and Influencing Factors in the 1980s", Journal of the International Listening Association, Vol. 4, 1990, pp. 62-82.

35. Bostrom, R.N. and Waldhart, E., "Components in Listening Behavior: The Role of Short-term Memory", Human Communication Research, Vol. 6, 1980, pp. 211-27.

36. Strauss, G. and Sayles, L., Personnel: The Human Problems of Management, Prentice-Hall, Englewood Cliffs, NJ, 1980.

37. Coakley, C.G. and Wolvin, A.D., "Listening Pedagogy and Androgogy: The State of the Art", Journal of the International Listening Association, Vol. 4, 1990, pp. 33-61.

38. Dessler, G., Human Behavior: Improving Performance at Work, Prentice-Hall, Reston, VA, 1985.

39. McGregor, D., The Human Side of Enterprise, McGraw- Hill, New York, NY, 1960. 40. Lundberg, C.C., "Towards Mapping the Communication Targets of Organizational Change", Journal of Organizational Change Management, Vol. 3 No. 3, 1990.

41. Nadler, D., Hackman, J.R. and Lawler, E.E. III, Managing Organizational Behavior, Little, Brown \& Company, Boston, MA, 1979.

42. Green, C.N., Adam, E.E. Jr and Ebert, R.J., Management for Effective Performance, Prentice-Hall, Englewood Cliffs, NJ, 1985.

43. Wolvin, A.D. and Coakley, C.G., Listening, William C. Brown, Dubuque, IA, 1992. 
44. Whetton, D. and Cameron, K., Developing Management Skills, Scott, Foresman \& Company, Glenview, IL, 1992.

45. Frank, A.D. and Brownell, J., Organizational Communication and Behavior: Communicating to Improve Performance, Holt, Rinehart and Winston, New York, NY, 1989.

46. Papa, M.G. and Tracy, K., "Communicative Indices of Employee Performance with New Technology", paper presented at the International Communication Association, Montreal, 1987.

47. Diffie-Couch, P., "Building a Feeling of Trust in the Company", Supervisory Management, Vol. 29 No. 4, April 1984, pp. 31-6.

48. Sherwin, D.S., "Strategies for Winning Employee Commitment", Harvard Business Review, Vol. 50 No. 3, 1972, pp. 37-47.

49. Kaiser, L.R., "Sensitive Managers Can Improve the Working Environment", Hospital Financial Management, Vol. 36 No. 3, March 1982, pp. 12-17.

50. Shea, G., Building Trust in the Workplace, American Management Association, New York, NY, 1984.

51. Leonards, J.T., "Corporate Psychology: An Answer to Occupational Mental Health", Personal and Guidance Journal, Vol. 60, 1981, pp. 47-51.

52. Campbell, K., "Listening to the Disfranchised", Proceedings, Cornell Conference on Listening: Multiple Perspectives, Cornell University, 1988.

53. Walton, R.E., "From Control to Commitment in the Workplace", Harvard Business Review, Vol. 64 No. 2, April 1985, pp. 77-84. 
54. Schlesinger, L. and Balzer, R., "An Alternative to Buzzword Management: The Culture Performance Link", Personnel, Vol. 62 No. 9, 1988, pp. 45-51.

55. Bruneau, T., "Empathy and Listening: A Conceptual Review and Theoretical Directions", Journal of the International Listening Association, Vol. 3, 1989, pp. 1-20.

56. Field, R.H.G. and Abelson, M.A., "Climate: A Reconceptualization and Proposed Model", Human Relations, Vol. 35 No. 3, 1982, pp. 181-201.

57. Daniel, T.L., "Managerial Behaviors: Their Relationship to Perceived Organizational Climate in a High-technology Company", Group \& Organization Studies, Vol. 10 No. 4, December 1985, pp. 413-28.

58. Lundberg, C.C., "On the Feasibility of Cultural Intervention in Organization", in Frost, P., Moore, A.L., Louis, M., Lundberg, C. and Martin, J. (Eds), Organizational Culture andthe Meaning of Life in the Workplace, Sage, New York, NY, 1985.

59. Schein, E.H., Organizational Culture and Leadership, Jossey-Bass, San Francisco, CA, 1985.

60. Schermerhorn, J.R., "Information Sharing as an Interorganizational Activity", Academy of Management Journal, Vol. 20 No. 1, 1977, pp. 148-53.

61. Peters, T. and Austin, N., A Passion for Excellence, Warner Books, New York, NY, 1985.

62. Allenbaugh, G.E., "Coaching: A Management Tool for a More Effective Work Performance", Management Review, Vol. 72 No. 5, May 1983, pp. 21-6.

63. Dastmalchian, A., "Environmental Characteristics and Organizational Climate: An Exploratory Study", Journal of Management Studies (UK), Vol. 23 No. 6, November 1986, pp. 609-33. 
64. Bruschi, P., "Getting it by Ear: Listening in the Training Process", Data Training, Vol. 5 No. 5, pp. 1-3.

65. Orr, D.B., "Note on Thought Rate as a Function of Reading and Listening Rate", Perceptual and Motor Skills, Vol. 19, 1964, pp. 872-86.

66. Shellen, W.N., "Some Evidence that Listening Tests Measure 'Normal' Listening”, The Journal of the International Listening Association, Vol. 3, 1989, pp. 62-71.

67. Carver, R., "Effect of Increasing the Rate of Speech Presentation upon Comprehension", Journal of Educational Psychology, Vol. 65, 1973, pp. 118-26.

68. Beatty, M.J., Behnke, R.R. and Froelick, D.L., "Effects of Achievement Incentive and Presentation Rate on Listening Comprehension", Quarterly Journal of Speech, Vol. 66, 1980, pp. 193-200.

69. Tumna, M.C., "A Comparative Review of Reading and Listening Comprehension", Journal of Reading, Vol. 23, 1980, pp. 698-703.

70. Howe, M., "Notetaking Strategy Review and Long-term Retention of Verbal Information", Journal of Educational Research, Vol. 63, 1970, pp. 284-8.

71. Carter, J. and Van Matre, N., "Note Taking vs. Note Having", Journal of Educational Psychology, Vol. 67, 1975, pp. 900-04.

72. DiVesta, F. and Gray, G., "Listening and Notetaking”, Journal of Educational Psychology, Vol. 63, 1982, pp. 8-14.

73. Bostrom, R.N., Listening Behavior: Measurement and Application, The Guildford Press, New York, NY, 1990.

74. Loftus, E., Memory, Addison-Wesley, Reading, MA, 1980. 
75. Basch, M.F., "Empathic Understanding: A Review of the Concept and Some Theoretical Considerations", American Psychoanalytic Association Journal, Vol. 31, 1983, pp. 101-26.

76. Broome, B.J., "Building Shared Meaning: Implications of a Relational Approach to Empathy for Teaching Intercultural Communication", Communication Education, Vol. 40 No. 2, 1991, pp. 35-249.

77. Howell, W.S., The Empathic Communicator, Wadsworth Publishing Company, Belmont, CA, 1982.

78. Stewart, J., "Interpretative Listening: An Alternative to Empathy", Communication Education, Vol. 32, 1983, pp. 379-91.

79. Larson, C.U., Persuasion: Reception and Responsibility, Wadsworth Publishing Company, Belmont, CA, 1989.

80. O'Keefe, D.J., Persuasion: Theory and Research, Sage Publications, Newbury Park, CA, 1990. Bradae, J. and Mulac, A., "A Molecular View of Powerful and Powerless Speech Styles", Communication Monographs, Vol. 51, 1984, pp. 307-19.

81. Johnson, C., "Ethical Implications of Powerful and Powerless Talk", Texas Speech Communication Journal, Vol. 14, 1989, pp. 7-11. 


\section{Appendix}

\section{Components of the HURIER Behavioral Listening Model Hearing/ Concentration}

The average person can listen and process information at a rate at least twice that of the normal speaker [65]. This means that most listeners have a good deal of "unused" mental time - time that is often spent daydreaming, rehearsing, or anticipating events and activities unrelated to the communication event at hand. Managers whose non-verbal behavior indicates that their attention is divided appear disinterested and preoccupied. Employees are likely to perceive these managers as poor listeners, regardless of whether or not their listening is effective when evaluated by other measures.

\section{Comprehension/Understanding}

Listening comprehension concerns the extent to which a message is literally understood. With increased specialization and technical vocabularies, comprehension has become an increasingly vital component of the listening process in organizational settings. Catering employees have to be able to communicate with sales and marketing, housekeeping employees with reservations, and so on.

Several standardized listening tests have been developed that measure aspects of listening comprehension [27], and numerous studies document their degree of validity and reliability [66]. Researchers and practitioners alike have been interested in the variables that affect listening comprehension and in the ways in which individuals can improve their understanding of the messages they hear [67-69]. Some of the most common methods include: learning effective organizational and note-taking systems, perception checking, and increasing vocabulary [70-72]. 


\section{Memory}

The ability to remember and recall is so closely linked to listening effectiveness that almost all models of the listening process include memory as a key component. Not only managers, but also all organizational members depend on their memory to perform tasks effectively; poor memory almost inevitably results in lower productivity and inefficiency.

Significant individual differences exist in the degree of competence individuals demonstrate in short-term (interpersonal) and long-term (presentational speaking) listening situations. Nevertheless, managers' ability to remember and recall what employees tell them is a key indicator in judgements of overall listening effectiveness. Those interested in improving their listening would do well to focus on developing more effective memory techniques $[73,74]$.

\section{Interpretation/Empathy}

An increasingly diverse workforce demands that greater emphasis be placed on interpreting messages, on going beyond understanding the substance of communication by taking into account the person speaking and his or her unique perceptions, attitudes, values, and experiences. Valuing diversity, a recurring theme, requires managers to attend to non-verbal cues and to be able to see things from another person's point of view. Listeners must understand and respect the person speaking before responding to his or her ideas.

Those studying empathy $[55,75-78]$ emphasize the importance of this othercentred perspective to the development and maintenance of effective relationships at work. 


\section{Evaluation}

Effective managers are perceived as open-minded; they have learned to withhold their evaluations until after they have heard and understood what others say. As employees become empowered to participate in decision-making processes, the quality of their judgements will have a greater impact on organizational effectiveness. Managers who are successful in creating strong listening environments recognize and work to reduce personal bias. They model desirable listening behaviors and set an example for their employees.

Individuals need to distinguish emotional appeals from valid evidence and logical argument; they must consider a wide range of factors in making their decisions $[79,80]$. Speaker variables, such as mannerisms, indicators of powerless speech, eye behavior, and other factors, must not interfere with judgements made about the value of the information presented [81, 82], nor must such indicators be interpreted without regard to cultural and individual differences.

\section{Response}

Recent models of communication suggest that the speaker/ listener dichotomy may be inaccurate; that is, individuals in communication encounters are simultaneously sending and receiving messages, processing incoming information as they formulate a response.

Behavioral models suggest that individuals make judgements about listening effectiveness based largely on their partner's verbal and non-verbal response to their messages. It is therefore useful to focus on the quality and appropriateness of the listener's response as a key element in the communication process. Managers must ask 
themselves: How do I respond when one of my employees asks for advice? Describes a personal problem? Misunderstands my directions? 
Table 1. Task and Relationship Dimensions of the Listening Environment

\section{Task-related}

- Improves selection of appropriate rewards

- Encourages more timely feedback

- Increases frequency of employee recognition

- Reduces misunderstandings, particularly when tasks are novel and/or changing

- Improves problem-solving ability

\section{Relationship-related}

- Increases interpersonal trust

- Increases information sharing

- Improves employees' mental health

- Reduces organizational game playing

- Increases employee commitment

- Increases accuracy of individual's self-perceptions 


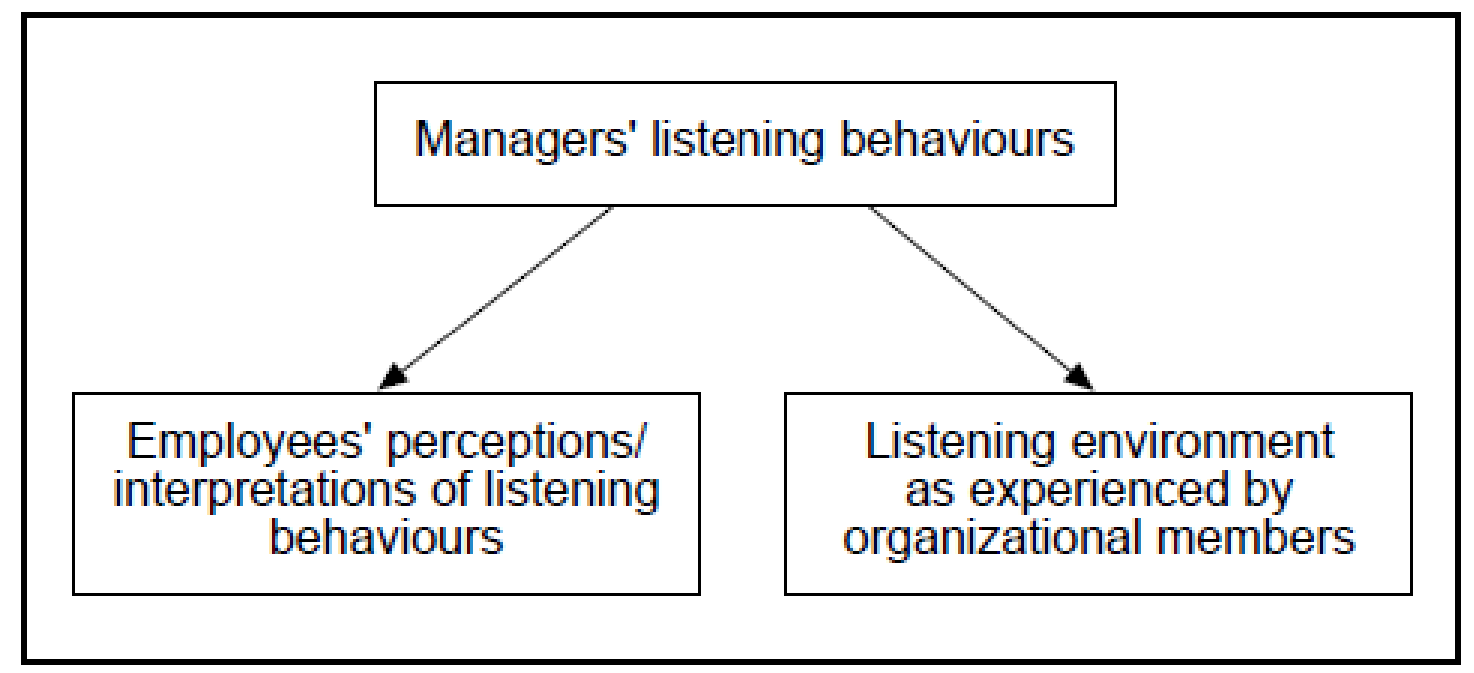

Figure 1. Creation of Listening Environments 


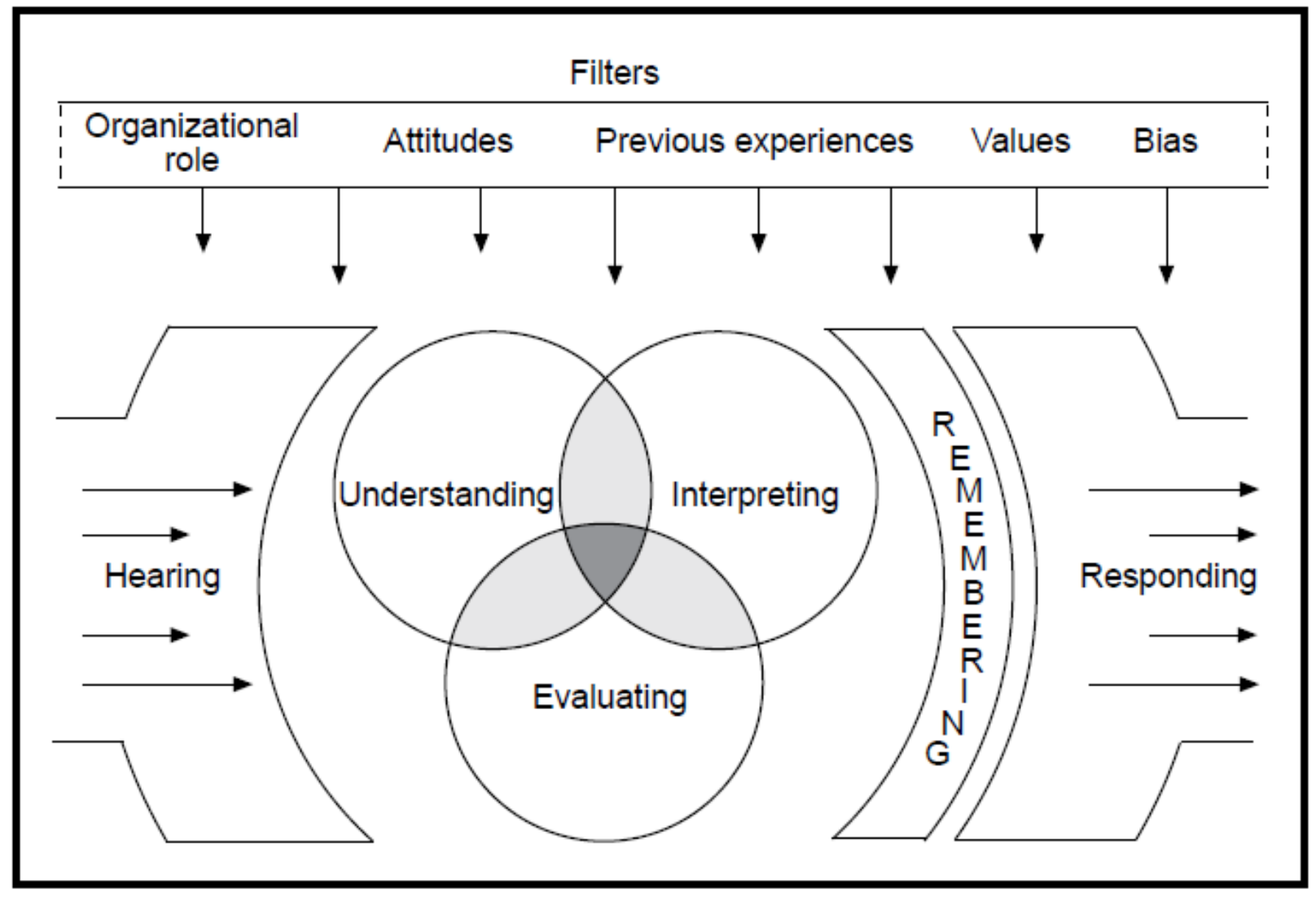

Figure 2. A model of the Six-component HURIER Listening Process 


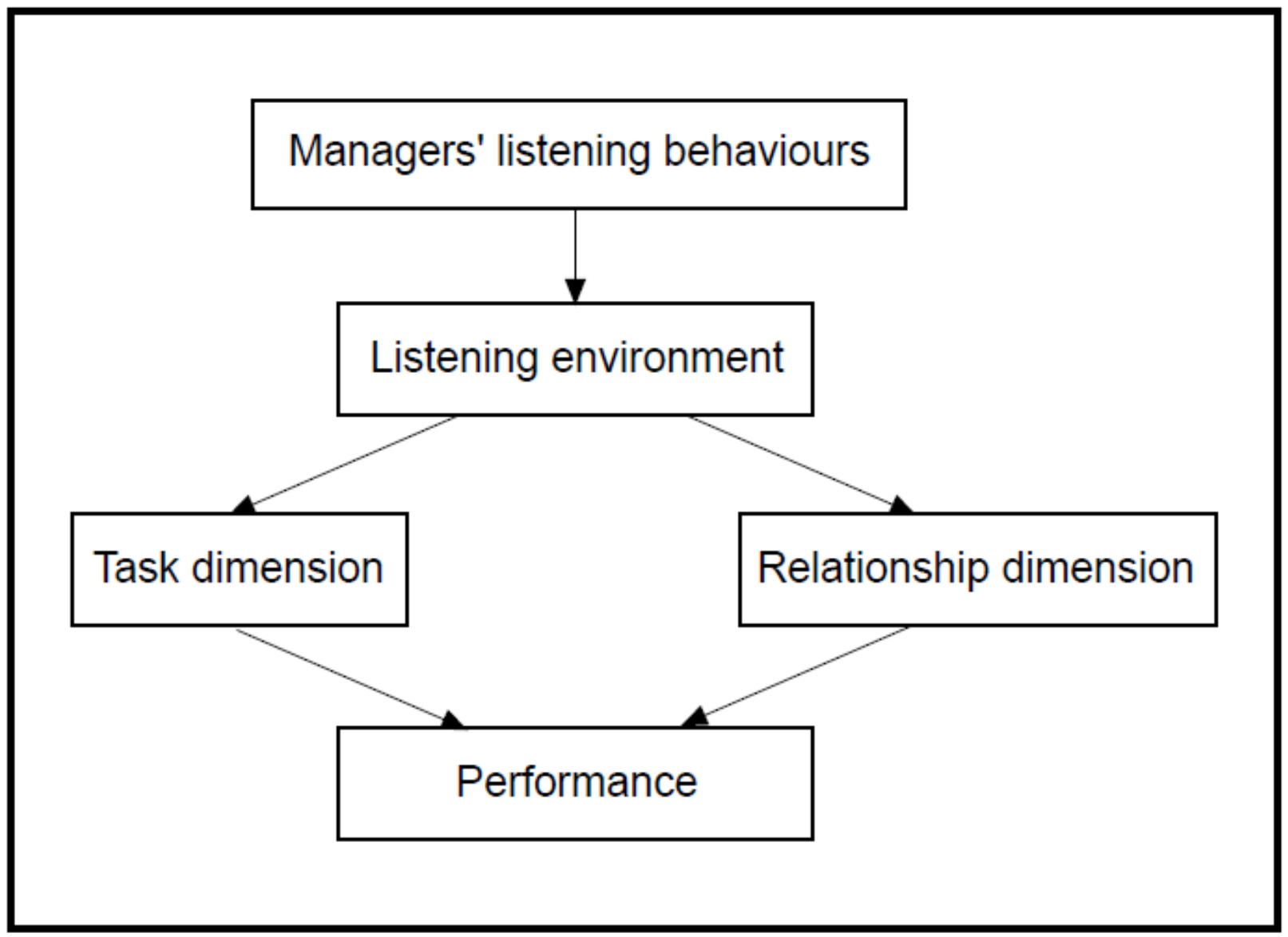

Figure 3. Influence of Listening Environments 